DOI: $10.2478 /$ rpp-2014-0036

PhD in Psychology, Associate Professor, KATERYNA SKYBA

Khmelnytskyi national university, Address: 11 Instytutska str., Khmelnytskyi, 29016, Ukraine E-mail: katrusyk@gmail.com

\title{
TRANSLATORS AND INTERPRETERS CERTIFICATION IN AUSTRALIA, CANADA, THE USA AND UKRAINE: COMPARATIVE ANALYSIS
}

\begin{abstract}
The article presents an overview of the certification process by which potential translators and interpreters demonstrate minimum standards of performance to warrant official or professional recognition of their ability to translate or interpret and to practise professionally in Australia, Canada, the USA and Ukraine. The aim of the study is to research and to compare the certification procedures of translators and interpreters in Australia, Canada, the USA and Ukraine; to outline possible avenues of creating a certification system network in Ukraine. It has been revealed that there is great variation in minimum requirements for practice, availability of training facilities and formal bodies that certify practitioners and that monitor and advance specialists' practices in the countries. Certification can be awarded by governmental or non-governmental organisations or associations of professionals in the field of translation/interpretation. Testing has been acknowledged as the usual avenue for candidates to gain certification. There are less popular grounds to get certification such as: completed training, presentation of previous relevant experience, and/or recommendations from practising professionals or serviceuser. The comparative analysis has revealed such elements of the certification procedures and national conventions in the researched countries that may form a basis for Ukrainian translators/interpreters certifying system and make it a part of a cross-national one.

Key words: translator, interpreter, translation, interpreting, certification, certifying system, certification procedure, translation and interpreting testing, translation and interpreting services.
\end{abstract}

\section{INTRODUCTION}

Discussion on quality assurances and credentialing for occupational groups is now commonplace in our globalized world. Marketplace needs, industry capabilities and availability of training facilities influence minimum standards and skill levels required for individuals to perform certain tasks. Professional associations and organizations may also play a role in the setting of standards. Profession of a translator/interpreter is very popular nowadays in Ukraine. Great amount of higher educational establishments are training specialists in the field of translation/interpretation in our country. All the graduates receive diplomas of the same kind but the quality of their training is very different. Thus except the educational institutions the existence of governmental and non-governmental organizations and associations of translators and interpreters certifying practitioners would be of great help. Australia, Canada, and the US have advanced certifying systems that help to promote professional recognition, foster the professional development of individual translators and interpreters, facilitate communication and establish standards of competence and ethics. The experience of the certifying organizations and associations in these countries may be compared and applied in Ukraine. 


\section{THE AIM OF THE STUDY}

The paper researches and compares the certification procedures of translators and interpreters in the USA, Canada, Australia and Ukraine; outlines possible avenues of creating a certification system network in Ukraine.

\section{THEORETICAL FRAMEWORK AND RESEARCH METHODS}

The Ukrainian scholars have researched peculiarities of professional training and professional standards of specialists in different fields in the following countries: the USA (N. Bidyuk, N. Mukan, O. Martynyuk), Canada (N. Mykytenko, A. Chyrva), Australia (S. Koreshkova, G. Slozanska), Great Britain (N. Avshenyuk, L. Pukhalovska, O. Serheeva), Germany (V. Bazova, L. Otroshchenko), China (N. Pazyura) and others. The following foreign researches have also undermined the issue of procedures of translators and interpreters certification: A. L. J. Chan, D. Gouadec, N. Kelly, H. Mikkelson, U. Ozolins, J. Stejskal, B. Turner. But the certification of translators and interpreters as a great means of professional recognition has not been researched in Ukraine yet. The comparison analysis of the national certifying systems of the country-leaders on the translation/interpreting services market and Ukrainian equivalent certification mechanism has not been fulfilled.

It is true, today translation and interpretation activity is subjected to regulatory standards in the same way that work practices in other fields of employment are. This is a global trend in which the practices and credentials of a service provider are measured and formally ascertained so that certain guarantees in regard to service quality in the marketplace can be made. We agree with J. Hlavac (2013) that in the first place, regulatory standards appear to offer protections primarily to service users, the consumers. However, regulatory standards also perform the function of formalising informal benchmarks of work practice within a profession.

In many countries, there are now authorities, either governmental or belonging to professional associations, which perform the regulation of standards. Regulation is performed on the basis of any or all of the following: evidence of training, formal testing, collected evidence of work performed, and recommendations from fellow practitioners. This type of regulation verifies individuals' capabilities to perform tasks for which they seek employment and is primarily intended to provide quality assurances for service-users and to "formalise" the profession. Recent research of translation agencies and vendors also indicates that certification of practitioners enhances a business's standing and increases the number of job offers received (Chan, 2010).

This overview is restricted to a limited number of countries. The choice of countries selected for the overview was determined based on their potential educational systems and advanced networks of formal bodies certifying translators and interpreters. The following foreign countries were selected on the basis of the attributes listed: Australia, Canada and the USA. The certifying procedures in the countries are compared with the Ukrainian equivalent mechanism of certification.

The research methods we used are: theoretical analysis, synthesis, the method of studying educational and historical documents.

\section{RESULTS}

In some countries, it is a governmental organisation that administers and conducts certification, in others a governmental organisation only administers certification and certification itself is conducted by another (usually professional) organisation. In other instances, there is little or no governmental regulation and certification of potential practitioners occurs only through professional organisation and/or tacitly or semi-officially through recognised training institutions (Halvac, 2013). Let's consider and compare the certifying systems in each of the chosen countries. 
In Australia, the certification process is administered by the National Accreditation Authority for Translators and Interpreters (NAATI), a not-for-profit company owned jointly by the Australian federal and all eight State and Territory governments. Certification reflects the governmental regulations that specify the standards of practice and level of proficiency that should be possessed by translation and interpretation practitioners contracted by institutions or organisations funded by federal, state or territory governments. NAATI certification has, tacitly, become a regulatory benchmark of translation and interpretation standards in Australia through governmental policy rather than legislation (Hlavac, 2013). There are four certification levels, the titles of which are NAATI (2011): Paraprofessional Translator/Paraprofessional Interpreter; Professional Translator / Professional Interpreter; Advanced Translator / Conference Interpreter; and Advanced Translator (Senior) / Advanced Interpreter (Senior).

There are five ways to gain NAATI certification: passing a NAATI accreditation test; successful completion of a course of studies in translation and/or interpreting at an Australian institution as approved by NAATI providing evidence of a specialised tertiary qualification in translation and/or interpreting obtained from an educational institution overseas; providing evidence of a membership of a recognised international translating and/or interpreting professional association; providing evidence of advanced standing in translating or interpreting.

In addition to translation or interpreting tasks, the NAATI test contains questions on ethics and knowledge of socio-cultural characteristics of Australian society and that or those of the countries or communities in which the other language is spoken/signed. We support the idea that socio-cultural competence of a translators or interpreters is of great importance as they are engaged in the process of interrelations of nations, cultures and traditions. So, the presence of such questions in the test witnesses the highly advanced level of NAATI testing. Most tertiary institutions that offer translation and interpreting training and a qualification have also been approved to conduct NAATI testing. Thus, testing is the usual avenue for candidates to gain NAATI certification.

In Australia, there are professional associations representing translation and interpreting practitioners in Australia. The main ones are AUSIT (the Australian Institute of Interpreters and Translators) and ASLIA (Australian Sign Language Interpreters' Association), with which NAATI has interconnections.

Canada is unique in the New World as a country with developed translation and interpretation training and services infrastructure to service the two official languages, while large numbers of speakers of further languages have necessitated the provision of translation and interpretation (usually community interpreting) services (Industry Canada, 2007).

In general, translation agencies in Canada are more likely to take on translators/ interpreters with university degrees and/or experience, but there is no legal requirement for translators/interpreters to be certified. The titles of "certified translator", "certified terminologist", ("terminologists" are specialists who identify, define and describe usually new terms that are to be used in a uniform and consistent way in both official languages) "certified interpreter", "certified conference interpreter", and "certified court interpreter" are granted by the provincial regulatory bodies for these professions. The Canadian Translators, Terminologists, and Interpreters Council (CTTIC, 2011) is responsible for the application of uniform standards for professional certification across Canada. CTTIC also administers the various exams that confer the right to use these titles. Three certification mechanisms are used in Canada: certification on dossier, certification by mentorship, and certification 
by exam (Hlavac, 2013). One of CTTIC's main roles is to ensure consistent application of certification with two objectives: to standardize methods of entry to the profession and to monitor the skills of translators belonging to provincial and territorial organizations. CTTIC administers a uniform translation exam based on the combined efforts of member bodies through the Board of Certification. The Board of Certification reports to CTTIC's Executive and sets requirements for certification. It also has general oversight over procedures and methods of assessing candidates.

In the USA, there is great variation in the number and type of translation and interpreting training programmes. These range from two-year post-graduate programmes at a dozen or so universities (e.g., Monterey established in 1965, Brigham Young established 1976, Florida International University in 1978, San Diego State in 1980) to 40-80 hour courses provided by local or state authorities (e.g., University of Massachusetts Worcester Campus Office of Community Programs, 2012; University of Texas at Austin Professional Development Centre, 2012), online learning programmes (Interpreter Education Online, 2012; Virginia Institute of Interpreting, 2012) and online service providers that specialise in an a specific area of T\&I services (e.g., Language Line, 2012). At the same time, there is a major difference between translation and spoken/signed interpreting: certification of the former is conducted by one major organization, the American Translators Association (ATA), while certification of the latter is performed by various state-based authorities, sometimes with further sub-distinctions based on field of interpreting (e.g., healthcare) or mode (e.g., signed interpreting) (HALVAC). Kelly (2007) provides a comprehensive and critical overview of the various types of certification and training available to would-be practitioners, and offers open recommendations to all stakeholders in the T\&I sector in the US. In recent years, many US universities appear to have introduced non-degree or certificate-level T\&I training, so that together with under-graduate and post-graduate programmes, there are now 105 programmes offered at 45 tertiary institutions across the US (TISAC, 2011).

The ATA offers certification tests to ATA members, who, along with other entry requirements, must provide evidence of translation and interpretation formal training as part of degree programme undertaken at a US or internationally recognised training facility. The ATA website provides a non-exhaustive list of worldwide training centres and programmes that it recognises. The ATA also accepts test candidates without a degree but with evidence of five years' translation and interpreting experience and letters of reference (ATA, 2012). It is a pleasure to know that among the List of Approved Translation and Interpreting Schools is Kharkiv State University (ATA, 2011).

With regard to court interpreting, the National Centre for State Courts (2009) manages the Consortium for Language Access in Courts, which in turn co-ordinates the testing of court interpreters in individual states. Although 40 of the 50 US states have signed up to the Consortium, only a dozen states have information on their testing centres online. The court interpreter test consists of sight translation into both languages, consecutive and simultaneous interpreting. There are now moves for interpreters with certification from one state to be granted recognition of their certification in other states (State of Connecticut Judicial Branch, 2012). There is a national-level professional organisation that represents the interests of court interpreters, the National Association of Judiciary Interpreters and Translators, which has over 1200 members (NAJIT, 2012).

Medical interpreting in the US "has progressed from an ad hoc function performed by untrained, dubiously bilingual individuals to a fledging profession concerned with standards of excellence and ethical practice" (Beltran Avery, 2003, 100). In 2009 the National Board 
of Certification for Medical Interpreters launched a national certification programme with written and oral tests for the following: written English proficiency, sight translation, consecutive interpreting, medical terminology, roles of the medical interpreter, cultural competence, knowledge of standards of practice, and legislation and regulations (National Board of Certification for Medical Interpreters, 2011). There are state-based associations of healthcare interpreters (e.g., Massachusetts Medical Interpreters Association) but for nearly 20 years, an umbrella organisation, the National Council on Interpreting in Health Care ( $\mathrm{NCIHC}$ ), has co-ordinated the interests of individual members and state-based associations. It has engaged with state- and nation-level healthcare policymakers to advance access, quality, and training in interpreting services. The activities of the NCIHC are characteristic of the prominence and culture of advocacy that local and specialist T\&I organisations in the US have gained. Thus, pre-requisites for membership often do not include formal training or even certification and the NCIHC as well as other similar organisations seek to attract other interest groups, academics, administrators, and sometimes even government agencies to their ranks (Hlavac, 2013).

Another development which originated in the US, and which now encompasses a very large number of T\&I professional organisations, as well as some employers and government agencies across the US and Canada, is the Translation and Interpreting Summit Advisory Council (TISAC), which was established in 1991. TISAC aims to "provide a vehicle for cooperation among organizations concerned with language translation and interpreting" (TISAC, 2011).

To sum up, in the USA the large number of certifying authorities and professional organisations that co-organise these or represent members who have gained certification suggests that certification is mandatory for work for state or national employers.

In Ukraine there are no governmental bodies to regulate certification of translation services. The activity of translators is regulated by the international and national standards in the field of translation operating in Ukraine: ISO 2384-77. Documentation. Translation design and State Standard of Ukraine - GOST 7.36-88. Unpublished translation. Coordination, general requirements and design rules.

The Ukrainian Translators Association (UTA) is the only one non-governmental organization that provides certification of translators and interpreters. The UTA was founded in 1999 in response to the urgent need to provide due quality of translation and interpreting services. UTA is an independent body for voluntary certification of translation and interpreting services, translators, and interpreters in the system of the State Committee of Ukraine for Standardization, Metrology, and Certification. In its activities, the UTA relies on domestic and international experience and strives to cooperation with organizations, which unite translators and interpreters worldwide.

Based on the results of the certification, companies, translators or interpreters are issued a Certificate of Compliance in the proper form. In addition, UTA issues Certificate of Full Member of Ukrainian Translators Association, which shall specify the area of language and subject competences of translator/interpreter/agency and individual's translation/ interpreting experience.

Written translators/interpreters (individuals) are admitted as full/corresponding members of UTA strictly upon passing of certification examination (evaluated by major experts in translation) whereas groups of translators and interpreters (agencies/centres/ departments) are admitted strictly subject to complying with the requirements laid down in standards STTU UTA 001-2000 (Qualification and Certification of Translators. General 
Requirements) and STTU UTA 002-2000 (Written and Oral Translation Services. General Rules and Requirements for the Service Provision) and/or subject to availability of valid quality system certified as per ISO 9000 system. Interpreters are admitted subject to compliance with the following requirements: at least 100 hours interpreting or recommendations of two customers (UTA, 2009). Nowadays the UTA has only nearly 60 full members and its activity as an all-Ukrainian association is very poor.

\section{CONCLUSIONS}

The comparison reveals that in some countries there are governmental or professional bodies that administer testing for the awarding of certification to translation and interpreting trainees or practitioners who can demonstrate minimum standards of ability and practice. In Australia, Canada, the USA and Ukraine the successful completion of a test is the usual minimum requirement for certification. The choice of the testing system as the main means of certification is stipulated by the pragmatic, needs-based and socially focussed policies of translation and interpreting services in the countries. There exist also some other mechanisms of certification. For example, in Canada there are such kinds of certification as on dossier, by mentorship and by exam. But it is necessary to point out that certification on dossier and by mentorship is not widespread along the country. It is performed only in several provinces of Canada. In the USA and Canada the certification may be specified according to general or specialized ability, or mode and context of interlingual transfer (e.g. "healthcare interpreter certification", "telephone interpreter certification", "terminologist", "conference interpreter"). In Australia there are no such specifications but there are four certification levels of the titles of which are: Paraprofessional Translator / Paraprofessional Interpreter; Professional Translator / Professional Interpreter; Advanced Translator / Conference Interpreter; and Advanced Translator (Senior) / Advanced Interpreter (Senior). Usually, the main prerequisite for membership in an organisation or association and certification includes formal training and evidences of translation/interpreting experience or recommendations of service-users. In Ukraine translators and interpreters as well as companies providing translation/interpreting services are issued a certificate of Compliance. The main requirements are outlined in the UTA statutes. Written translators must pass a certification exam while interpreters must have at least 100 hours interpreting or recommendations of service-users.

Thus, drawing parallels between the certification procedures and national conventions in the researched countries, we can find such elements that may form a basis for Ukrainian translators/interpreters certifying system that will be a part of cross-national one. To build a well organised network of organisations and associations of translators and interpreters it is advisable to start with the governmental policy that should be focused on quality of translation/interpretation services performance. As a result of the research, it was found out that the formal testing is the most frequently used and convenient means of certification. The tests should check not only the knowledge in translation and/or interpreting studies but also contain questions on ethics and socio-cultural peculiarities of Ukrainian society and that or those of the countries or communities in which the other language is spoken. The certification should also be specified according to particular field or industry that interpreters and translators specialize in (e.g. conference interpreters, guide or escort interpreters, health or medical interpreters and translators, legal or judiciary interpreters, literary translators, localizers etc.). We strongly believe the certification will not only formalise translation and interpretation services, it will also attract potential practitioners to undergo certification procedure to measure their own abilities and to demonstrate them to others. 


\section{REFERENCES}

1. ATA [American Translators' Association]. (2012). ATA Certification Program. Retrieved 10.06.2014 from: http://www.atanet.org/certification/eligibility_requirementsform.php.

2. ATA [American Translators' Association]. (2011). List of Approved Translation and Interpreting Schools. Retrieved 10.06.2014 from: http://atanet.org/certification/eligibility_ approved.php\#ukr.

3. Beltran Avery, M.-P. (2003). Creating a high-standard, inclusive and authentic certification process. In: Brunette, L., Bastik, G., Heinlik, L. \& Clarice, H. (Eds.), The Critical Link 3: Interpreters in the Community. Amsterdam: John Benjamins, p. 99-112.

4. Chan, 2010 Chan, A. L. J. (2010). Perceived benefits of translator certification to stakeholders in the translation profession: a survey of vendor managers. Across Languages and Cultures. Volume 11, Number 1, p. 93-113. Retrieved 25.06.2014 from: Universitat Rovira I Virgili URV Library, DOI: 10.1556/Acr.11.2010.1.6.

5. CTTIC [Canadian Translators, Terminologists and Interpreters Council]. (2011). Candidate's guide for the critic standard certification examination in translation. Retrieved 17.06.2014 from: http://www.cttic.org/examDocs/guide.candidatesE.pdf.

6. Hlavac, James. (2013). A Cross-National Overview of Translator and Interpreter Certification Procedures. The International Journal of Translation and Interpreting Research, Volume 5, Number 1, p. 32-65. Retrieved 25.06.2014 from: Translation and Interpreting.org, DOI:10.12807/ti.105201.2013.a02.

7. Industry Canada. (2007). Community interpreting in Canada. Retrieved September 20, 2014 from: http://www.ic.gc.ca./epic/site/lain-inla.nsf/en/h_gs002293.html.

8. Kelly, N. (2007). Interpreter Certification Programs in the U.S. Where are we headed? The ATA Chronicle (January, 2007), p. 31-39. Retrieved 15.07.2014 from: http://www.atanet.org/chronicle/feature_article_january2007.php.

9. NAATI [National Accreditation Authority for Translators and Interpreters]. (2011). Methods of NAATI accreditation. Retrieved 3.07.2014 from: http://www.naati.com.au/ accreditation.html.

10. NAJIT [National Association of Judiciary Interpreters and Translators]. (2012). The National Association of Judiciary Interpreters and Translators. Retrieved 3.07.2014 from: http://www.najit.org/index.php.

11. National Board of Certification for Medical Interpreters. (2011). Written exam. Retrieved 15.06.2014 from: http://www.certifiedmedicalinterpreters.org/written-exam.

12. State of Connecticut Judicial Branch. (2012). Court interpreter and translator services. Retrieved 10.06.2014 from: http://www.jud.state.ct.us/external/news/jobs/ interpreter. htm\#Certified.

13. TISAC [Translation and Interpreting Summit Advisory Council]. (2011). TnI programs database. Retrieved 15.06.2014 from: http://www.tisac.org/programs/.

14. Ukrainian Translators Association. (2012). General Information. Retrieved 15.06.2014 from: http://www.uta.org.ua/en/general_information. 